\title{
Comparing Vulnerability to Poverty: A Case Study in the Northern Region of Malaysia
}

\author{
Jamalludin Sulaiman ${ }^{1}$, Azlinda Azman ${ }^{1}$, Abdelhak Senadjki ${ }^{2, *}$ \\ ${ }^{1}$ School of Social Sciences, Universiti Sains Malaysia, 11800 Penang, Malaysia \\ ${ }^{2}$ Universiti Tunku Abdul Rahman, 31900 Perak, Malaysia \\ *Corresponding Author: abdelhak@utar.edu.my
}

\begin{abstract}
Malaysia has effectively succeeded in reducing the incidence of poverty from high of 50 percent in the 1950 s to less than 10 percent currently. Poverty is also a regional phenomenon in Malaysia. In less developed states in the northern region of Malaysia (which includes the states of Perlis, Kelantan and Terengganu), both poverty and a wide variety of risks are widespread among household member, especially in the rural areas. These make them more vulnerable overtime. This study argued that households have different set of tools or behavior to overcome these shocks and manage the onset and the consequences of the risks. However, the degree of their behavior pattern depends on the differential access to various types of assets and entitlements. Three rounds of panel data analysis on a sample of 170, 202 and 101 farmers in Perlis, Terengganu and Kelantan respectively provides the socio-economic profile of the population while estimating and comparing the Vulnerability as Expected Poverty among the 3 selected states. The results confirmed the presence of vulnerability to poverty among farmers in the communities studied. As there are factors that significantly contribute to farmers' vulnerability reduction such as land size, loans, mechanization, subsidies in fertilizers and spend saving in productive assets; also there are some strategies (sell of natural resources, sell of productive assets and sell of non-productive assets) that implemented by farmers that were the main cause for their impoverishment. These strategies were counter-productive rather than productive. The findings of the present study argued that in order to eradicate poverty from the Malaysian society, policymakers should add to the present anti-poverty schemes (which are ex-post in nature) programs that are ex-ante in nature. The ex-ante programs have the ability to target the non-poor people today to protect their future human rights.
\end{abstract}

Keywords Poverty, Vulnerability, Longitudinal Data, Farmers, Northern Region of Malaysia

\section{Introduction}

Poverty and income inequality have always been a major policy concern in Malaysia. Poverty incidence in Malaysia has reduced significantly from a high of 50 percent in the 1950s to less than 10 percent currently. Poverty is also a regional phenomenon in Malaysia. In the less developed states of the northern region of Malaysia (which includes as Perlis, Kelantan and Terengganu), both poverty and a wide variety of risks are widespread among household members, especially in the rural areas. These make them more vulnerable over a period of time. Households implemented different tactics in dealing with these risks. The effectiveness of their interventions depends on the nature of risks and uncertainties as well as on households' abilities, capabilities and capacities. Literatures have revealed that the agriculture sector in Malaysia is the most vulnerable sector to risks and uncertainties due to climate change (Alam et al., 2011a; Alam et al., 2011b; Alam et al., 2012). Exposing to risks and calamities such as floods, droughts, excessive rain and pest and diseases directly and indirectly harm farms productivity and production. In some cases the negative impact of such calamities cause a massive destruction to crop yield such as paddy, rubber, oil palm and Cocoa (Al-Amin et al., 2011). Other risks such as increase temperature, weeds, injurious insects, soil fertility, drainage water supply, and cost of inputs, labor scarcity and paddy prices contributing to the deterioration of household's livelihoods (Alam et al., 2011a). These risks are frequently occurring especially in Perlis, Kedah, Kelantan and Terengganu (Siwar et al., 2009a; Alam et al., 2010). Terengganu, Kelantan, Perlis, Kedah and Perak are the most vulnerable states that have relatively higher levels of hardcore poverty and projected temperature as well as rainfall changes (Begum et al., 2011).

This study argues that the lack and inadequate access to assets and entitlements made the process of escaping poverty more complex. The ineffective impact of programs of institutions in these communities also contributed to slow down the process of eradicating poverty from these communities (Jamalludin et al., 2012; Abdelhak et al., 2012a). These make rural population more vulnerable to poverty. Another reason that slows the process of eradicating poverty from these states is because most of policies that addressed poverty problems were ex-post in nature. These policies only targeted the poor and the hardcore poor and 
ignored vulnerable people who are not poor today but under some circumstances they may become poor in future. Targeting only the hardcore poor and the poor apparently may lead to enhance their wellbeing and then get them rid out of poverty. Ignoring the vulnerable groups also make the effort of poverty alleviation less productive as the vulnerable groups might become poor in future. As these programs are not forward-looking oriented (ex-ante in nature) they cannot capture the vulnerable groups. Poverty eradication effort in Malaysia may become more challenging when non-static (dynamic) poverty or vulnerability dimensions are considered in policy implication. Vulnerability became one of the major obstacles to social and economic development. It is argued that sustainable poverty reduction could be achieved only if vulnerability assessment integrated to the agenda of poverty eradication (IDS, 2013).

Vulnerability lacks a common methodology that can adequately measure it. Many researchers developed different methodologies (Chaudhuri, 2003; Glewwe \& Hall, 1998; Christiansen \& Boisvert, 2000; Chaudhuri et al., 2002; Ligon \& Schechter, 2003; Calvo \& dercon, 2005; Gunther \& Harttgen, 2009; Ersado, 2006; Dutta et al., 2010). These methodologies are found to be ineffective in analysing vulnerability since most of these methodologies do not take in consideration the role of risks in vulnerability assessment. Indeed the methodologies that consider in their analysis the role of risks (which is assumed to be the error term) cannot be used as an appropriate tools that explain the mechanism of how households move in and out of poverty since these methodologies are designed based on cross-section surveys such as LSMS that only account for a small fraction of the potential number of topics on risks or vulnerable groups (Hoogeveen et al., 2004). The only information can be provided by these surveys are consumption and income information and some households' socio-economic characteristics such as gender, education. The actual measurement of vulnerability requires better data analytical methods (Heitzmann et al., 2002). There is a need to develop approaches that can overcome the limitations of cross sectional data (Hoogeveen et al., 2004). To measure vulnerability, panel data need to be supplemented to measure things such as risk and household responses (Alwang et al., 2002).

Using the ex-ante multidisciplinary approach, a set of household socio-economic data was collected to estimate Vulnerability as Expected Poverty (VEP). Three rounds of panel data analysis on a sample of 170, 202 and 101 farmers in Perlis, Terengganu and Kelantan respectively provides the socio-economic profile of the population while estimating and comparing the Vulnerability as Expected Poverty among the 3 selected states. This study seeks to answer the following questions: (1) why vulnerability differs from state to state in northern region of Malaysia? (2) What factors that significantly made these differences? (3) Are differences in households' perceptions and behaviours the main cause of various vulnerabilities level? Or is it the households' capacities?

Poverty in Malaysia is determined by the Poverty Line Income (PLI) of RM194 per month per capita $\left(10^{\text {th }}\right.$ Malaysia Plan). A household is considered poor if his income is less than the PLI, indicating that the individual lacks the resources to meet the basic needs.

\section{Methodology}

This study employed Chaudhuri (2003) and Chaudhuri et al. (2002) definition of vulnerability as Vulnerability as Expected Poverty (VEP) as the probability of households to fall into poverty in the future. Thus, vulnerability of household $i$ at time $t$ can be written as:

$$
\operatorname{VEP}_{\mathrm{t}}^{\mathrm{i}}=\operatorname{Pr}\left(\mathrm{I}_{\mathrm{t}+1}^{\mathrm{i}} \leq \mathrm{PLI}\right)
$$

Where $\mathrm{I}_{\mathrm{t}+1}^{\mathrm{i}}$ is the per capita income of household at $\mathrm{t}+1$ time and PLI is the poverty line income.

It is assumed that household's per capita income is a function, in general, of household's capacities (Assets), idiosyncratic and covariate risks that household's experienced, household's abilities to cope with and manage against these risks and institutions' supports. Assuming that per capita income is log-normally distributed, therefore household i's per capita income could be expressed as follows:

$$
\operatorname{Ln} \mathrm{I}_{\mathrm{t}+1}^{\mathrm{i}}=\mathrm{X}_{\mathrm{ijt}} \beta_{i j t}+\theta_{\mathrm{ijt}}
$$

While:

$$
\begin{array}{r}
\mathrm{X}_{\mathrm{ijt}}=\left(\mathrm{A}_{\mathrm{ijt}} \alpha_{\mathrm{f}}+\mathrm{CR}_{\mathrm{ijt}} \beta_{\mathrm{k}}+\mathrm{IR}_{\mathrm{ijt}} \gamma_{\mathrm{l}}+\mathrm{RMS}_{\mathrm{ijt}} \delta_{\mathrm{m}}+\right. \\
\left.\mathrm{CS}_{\mathrm{ijt}} \partial_{\mathrm{n}}+\mathrm{IS}_{\mathrm{ijt}} \tau_{\mathrm{o}}\right) \ldots \ldots \ldots \ldots(3)
\end{array}
$$

Where $\operatorname{Ln} \mathrm{I}_{\mathrm{t}+1}^{\mathrm{i}}$ is the future per capita income, in normal log; $\theta_{\text {ijt }}$ represents the unobserved permanent earning determinant as well as the transitory component of earnings (Bourguignon et al., 2004). $A_{i j t}$ represents households' capacities (Assets) of household $\mathrm{i}$ in cohort $\mathrm{j}$ at time $\mathrm{t}$; $\mathrm{CS}_{\text {ijt }}$ represents households' coping strategies and $\mathrm{RMS}_{\mathrm{ijt}}$ represents household's risk management strategies. $C R_{i j t}$ represents the covariate risks that households were exposed to and similarly, $I_{\mathrm{ijt}}$ represents the idiosyncratic risks. While $\mathrm{IS}_{\mathrm{ijt}}$ represents the institutional supports, $\tau_{\mathrm{o}}, \beta_{\mathrm{k}}, \gamma_{\mathrm{l}}, \delta_{\mathrm{m}}, \partial_{\mathrm{n}}, \alpha_{\mathrm{f}}$ are vector of parameters.

Accordingly, we assume that the residual term $\theta_{\mathrm{ijt}}$ follows an autoregressive process $\mathrm{AR}(1)$ (Bourguignon et al., 2004):

$$
\theta_{\mathrm{ijt}}=\rho_{i} \theta_{\mathrm{ijt}-1}+\varepsilon_{\mathrm{ijt}} \ldots \ldots \ldots \ldots \ldots \ldots . .(4)
$$

Where $\varepsilon_{\mathrm{ijt}}$ is the innovation in earnings and is supposed to have a variance $\sigma_{\varepsilon i j t}^{2}$

Following Bourguignon et al. (2004) procedure then the Vulnerability As Expected Poverty (VEP) can be calculated as:

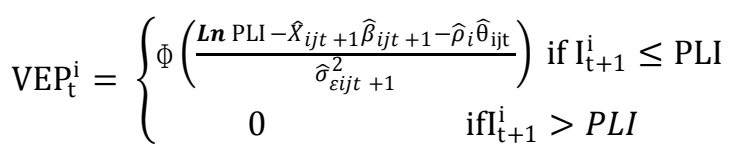


With $\Phi$ is the cumulative log-normal distribution function

A household who has a VEP equals 0.5 and greater is considered vulnerable to poverty and may not be able to get out of his or her poverty in the immediate future (Chaudhuri et al., 2002).

\section{Data}

Data was collected from a three-round panel survey undertaken at 6 month interval to allow for seasonal variation in behavior and outcome and to balance both cross-sectional and time series requirements of panel data. For the Terengganu and Kelantan states, the first round data collection was done in December 2010 with 260 and 200 questionnaires distributed in the respective states. In June, 2011 only 146 and 140 respondents respectively were reachable in the second survey round. In January 2012, only 218 and 110 questionnaires were completed respectively as the missing respondents were unreachable. From these 218 and 110 questionnaires only 201 and 100 respectively were valid for data analysis. The remaining (27) dropped from the analysis as they were incomplete and caused some statistical problems. For the Perlis state, the first survey round was in October 2011 with 213 questionnaires distributed. In May 2012, only 194 respondents were reachable in the second survey round. In January 2013, only 170 questionnaires were completed as the missing respondents were unreachable.

\section{Results}

\section{Comparing vulnerability and poverty in Kelantan, Terengganu and Perlis}

Table 1 illustrates the cross distribution between poverty and vulnerability in Kelantan, Terengganu and Perlis. As showed in table 1, farmers moved in and out of poverty. The results indicated that paddy farmers in Perlis are the poorest people $(78.20 \%)$ followed by Kelantan farmers $(73.07 \%)$ then Terengganu farmers $(48.3 \%)$.

Based on the study, close to two thirds (64.4\%) of Kelantan farmers and about half (51.8\%) of Perlis farmers were likely to become poor in future. On the other hand, only about a third (28.4\%) of Perlis farmers was vulnerable.

Of the farmers surveyed in the three states, more of the poor farmers were most likely to remain poor, thus chronic poverty. The highest percentage was poor farmers in Terengganu (79.16\%), followed by Kelantan poor farmers (57.14\%). About half (48.46\%) of Perlis poor farmers was likely to remain poor, according to the study. The non-vulnerable were mostly the non-poor in the states, except in Perlis where the number was about equal. The vulnerable non-poor is said to fall into transient poverty when their VEP equals or greater than 0.5.

Details of the other categories of vulnerable poor and non-poor and the non-vulnerable poor and non-poor are presented Table 1.

Table 1. Cross-Distribution Between Poverty and Vulnerability $(\mathrm{VEP} \geq 0.50)$

\begin{tabular}{|c|c|c|c|c|}
\hline & & $\begin{array}{c}\text { Non-vulnerable } \\
\text { to poverty }\end{array}$ & $\begin{array}{l}\text { Vulnerable } \\
\text { to poverty }\end{array}$ & \\
\hline \multirow{3}{*}{ Kelantan } & Overall & $35.60 \%$ & $64.40 \%$ & $100 \%$ \\
\hline & Poor & $42.86 \%$ & $57.14 \%$ & $73.07 \%$ \\
\hline & Non-poor & $65.26 \%$ & $34.74 \%$ & $26.93 \%$ \\
\hline \multirow{4}{*}{ Terengganu } & Overall & $71.6 \%$ & $28.4 \%$ & $100 \%$ \\
\hline & Poor & $20.84 \%$ & $79.16 \%$ & $48.3 \%$ \\
\hline & Non-poor & $65.39 \%$ & $34.61 \%$ & $51.7 \%$ \\
\hline & Overall & $48.2 \%$ & $51.8 \%$ & $100 \%$ \\
\hline \multirow{2}{*}{ Perlis } & Poor & $51.35 \%$ & $48.46 \%$ & $78.2 \%$ \\
\hline & Non-poor & $47.36 \%$ & $52.63 \%$ & $21.8 \%$ \\
\hline
\end{tabular}

Table 2. Vulnerability as Expected Poverty (VEP) Distribution within Different Socio-Demographic Variables

\begin{tabular}{|c|c|c|c|c|}
\hline & \multicolumn{4}{|c|}{$\mathrm{VEP} \geq 0.50$} \\
\hline & & $\begin{array}{c}\text { Kelantan } \\
(\%)\end{array}$ & $\begin{array}{c}\text { Terengganu } \\
(\%)\end{array}$ & Perlis (\%) \\
\hline \multirow[t]{4}{*}{ Age } & $31-45$ & 39.13 & 35.28 & 50 \\
\hline & $46-60$ & 39.37 & 34.23 & 53.33 \\
\hline & $\begin{array}{c}\text { More than } \\
61\end{array}$ & 42.30 & --- & 50 \\
\hline & Male & 64.40 & 30.36 & 51.44 \\
\hline \multirow[t]{2}{*}{ Gender } & Female & -- & 22.22 & 53.12 \\
\hline & 2 to 4 & 36.73 & 19.73 & 50 \\
\hline \multirow[t]{4}{*}{ HH size } & 5 to 7 & 34.61 & 36.36 & 52.38 \\
\hline & 8 to 9 & 35.64 & 33.33 & 60 \\
\hline & $\begin{array}{l}\text { No formal } \\
\text { education }\end{array}$ & 34.6 & 38.0 & 50 \\
\hline & STD 5/6 & 28.57 & 33.33 & 49.05 \\
\hline \multirow[t]{2}{*}{ Edu. Level } & PMR/LCE & 31.8 & 30.2 & 48.61 \\
\hline & SPM/MCE & 33.0 & 32.1 & 58.1 \\
\hline
\end{tabular}

The results of Table 2 indicate the distribution of farmers' vulnerability within their socio-demographic standing.

About equal numbers $(50 \%)$ of the vulnerable groups in Perlis were in the different categories (by age groups, gender, household size and education) as listed in table 2. In Kelantan and Terengganu, the percentages were between 20 and 38, except that more than half $(64.4 \%)$ of the Kelantan males, were most vulnerable with VEP equals or more than 0.5 . Thus it is rather inclusive to determine the most vulnerable group within the socio-demographic profile of the 
respondents.

\section{The Determinants of Vulnerability to Poverty in Kelantan, Terengganu and Perlis}

To determine the impact of various variables such as farmers' assets and their coping and risk management strategies on farmers' vulnerabilities, a multiple regression analysis was conducted. Vulnerability to poverty (VEP) is calculated from formula 5, household size measured the number of individuals living in same house sharing same income, many of times required hospital measured as the number of times the productive household have obtained treatment from hospital when sick, land sized measured as number of acres that farmer own or manage, source of fertilizers is a dummy ( 1 if farmers get subsidized and 0 otherwise), source of water is a dummy ( 1 if farmer have proper irrigation system and 0 otherwise) source of tilling is a dummy ( 1 if farmers use mechanical cultivation and 0 otherwise). Risk reduction strategies are strategies that were used by farmers before risks occur and they used to reduce the impact of risks on farmers' wellbeing. Risk mitigation strategies are strategies that used by farmers before risks occur and they are used to mitigate the impact of risks on farmers wellbeing. Coping strategies are strategies implemented after risks occur and they are used to compensate the losses caused by various risks and uncertainties.

The results of table 3 reveal that the regression models 1, 2 and 3 are significant $(F=17.778, p=0.000), \quad(F=25.568$, $\mathrm{p}=0.000)$ and $(\mathrm{F}=11.883, \mathrm{p}=0.000)$ respectively. The coefficient determination $\left(\mathrm{R}^{2}\right)$ is equal to $0.824,0.735$ and 0.604 for model 1, 2 and 3 respectively. This means that 82.4, 73.5 and 60.4 percent of farmers' vulnerability in model 1, 2 and 3 respectively are explained by the selected predictors. The results of table 3 indicate that household size, number of times farmers being helped, saving at home or in bank, source of water variables are not a determinant of farmers' vulnerability as all these variables show no significant impact on farmers' vulnerability in the three states. These results are consistent with the observation made earlier based on the socio-demographic profiles of the respondents.

Other indicators of vulnerability are as follows. For every additional time that the farmers require hospitals treatments, their probability of being poor in future increased by 0.183 (Kelantan) and 0.249 (Terengganu) points. Hospitalization did not affect Perlis farmers significantly.

Land size is an important asset that can mitigate farmers' vulnerabilities. The results showed that an increase of 1 acre in land size led to a decrease farmer's vulnerability by 0.308 and 0.784 point in Kelantan and Terengganu, respectively.

Subsidies (fertilizers) did not play any significant role in both Terengganu and Perlis. Using mechanical in farming activities has a prominent role in reducing farmers' vulnerability. The results of table 3 indicated that when farmers use mechanical cultivation then their vulnerabilities decrease by $0.110,1.987$ and 1.390 points in Kelantan, Terengganu, and Perlis, respectively.

None of the risk mitigation and risk reduction strategies showed any significant effect on farmers' vulnerabilities. For details please Table-1 in Appendix

However, coping strategies (reducing diet and reducing expenditures in luxury items) showed some significant impact on farmers' vulnerabilities. The results of table 3 revealed that when farmers reduce diet then their vulnerabilities reduce by 0.304 and 1.842 points in Kelantan and Terengganu respectively, except in Perlis where the result was insignificant. Similarly, farmers' vulnerability reduction due to reducing expenditures in luxury items reduced by 1.074 and 1.761 points in Kelantan and Terengganu, respectively. The result was not significant for Perlis.

Selling of natural resources is a counterproductive strategy, according to this study. When farmers engage in collecting then selling natural resources from forest and fisheries, then their vulnerabilities increased by 0.192 (Kelantan), 2.473 (Terengganu) and 0.108 (Perlis) points. Selling of non-productive assets also increased farmers' vulnerability by 2.224 points in Terengganu while this strategy showed no significant impact in both Kelantan and Perlis.

Selling of productive assets, on the other hand, increased farmers' vulnerability by 0.134 and 4.001 points in Kelantan and Terengganu, respectively but was not significant in Perlis. Using saving to purchase productive asset led to decrease farmers' vulnerabilities by 0.076 and 0.719 points in Kelantan and Terengganu, respectively.

Perlis farmers reduced their vulnerabilities by getting loans by 0.122 point. Also get loan from third party led to decrease farmers' vulnerability by 0.122 point in Perlis but not in Kelantan and Terengganu. Assistance from institutions had no significant impact on farmers' vulnerability in Kelantan, Terengganu or Perlis.

\section{Discussion}

The results in table 1 indicate that farmers' movement in and out of poverty is present among all the communities in the three states studied although at different levels. Thus, in order to eradicate poverty from the Malaysian society, policy maker should include to the present anti-poverty schemes programs that are ex-ante in nature. These programs have the ability to target the non-poor people today that may, under some conditions, become poor in future. It is not enough to just focus only on the poor and exclude the vulnerable population. The marginalized non-poor group may become poor in future if only such strategies are implemented.

Comparing vulnerability based on age factor, the results of table 2 showed that in Kelantan, Terengganu and Perlis there is not much difference in the proportion of vulnerable farmers in different age groups. Previous studies argued that age is an important factor that can determine farmers' level 
of poverty. This is due to the fact that older farmers' health condition is not as young farmers. As farming activities depends mainly on health conditions, especially in cases where farmers depends only on manual farming, the older farmers are less productive and cannot afford the difficulties faced in their daily farm activities.

However, results from this study are not consistent with the above statement. Older farmers do not necessarily do all the farm work themselves, but may employ younger and more physically able workers to do the activities that require strong physical efforts or hire tractors and other mechanical devices to do the jobs. Such strategies are available in the three states.

For the gender factor, the results of table 2 also indicate that there is no difference in the proportion of vulnerability between female-headed and male headed farmers. In Malaysia females are active as much males in different economic activities including the agriculture sector. Female-headed farmers participate in different farm activities and attend various educational and training agricultural programs and schemes. This makes them good managers and enhances their abilities in managing their farms and households. Again, there is no difference of the proportion in farmers' vulnerability among household-size group in all the states. This was enforced by the results from table 3 as there was no significant impact of household-size on the level of farmers' vulnerabilities. Theories and previous studies indicate that large household-size characterized with higher level of poverty. This is not always true, as in many cases; in large families there is more than one productive member which also can generate income to the family (it is considered as an asset to the family i.e human capital). In addition there is no difference in vulnerabilities between farmers with or without formal education.

These results reject the human capital theory that signifies that education is an important factor that contributes to poverty eradication (Fafchamps \& Quisumbing, 1988; Bokosi, 2007; Owuor et al., 2007) and supported Abdelhak et el. (2012b), Wie (2001) findings. It is therefore farmers' level of skills and good practices and management that increase farmers' productivity and production which in turn boost farmers' revenues and income while minimizing their vulnerabilities.

Table 3 illustrate some statistical findings that could be a road-map to answer why vulnerabilities is differ from state to state as indicated in table 1 and table 2 . The insignificant effect of farmers' social capital (number of time farmer being helped) on farmers vulnerabilities in the three states can be explained by the fact that farmers in these communities characterized by high level of poverty. As most of farmers live below poverty level, it is very difficult to obtain help from friends and relatives. Indeed, in such communities institutions role was inefficient in protecting people from being vulnerable. Abdelhak et al. (2012a) found that in Kelantan and Terengganu, institutions do not play significant role in strengthening households' capacities. This results confirmed as findings in table 3 indicate that get assistance from institutions have insignificant impact on farmers' vulnerabilities in the three states studied.

\section{Conclusion}

The present study shed some lights on the issue of vulnerability to poverty. While previous studies analyzed and assed vulnerability to poverty using cross sectional data, this study went one step forward by assessing vulnerability using longitudinal data collected from paddy, fruit and vegetable farmers in the most poor states in Malaysia include Kelantan, Terengganu and Perlis. The present study confirmed farmers' movement in and out of poverty among all the communities in the three states studied although at different levels. Thus, in order to eradicate poverty from the Malaysian society, policy maker should add to the present anti-poverty schemes programs that are ex-ante in nature. These programs have the ability to target the non-poor people today that may, under some conditions, become poor in future. It is not satisfactory to focus only on the poor and exclude the vulnerable people as this strategy will be less effective due to the marginalized non-poor group will become poor in future if non efficient strategies are implemented. Tackling farmers' vulnerabilities is also the responsibility of farmers themselves. The results depicted that some of the strategies that implemented by farmers were the main cause for their impoverishment which in turn led to increase their level of vulnerabilities.

\section{Acknowledgment}

This research was funded by the Ministry of Higher Education Malaysia under the Fundamental Research Grant Scheme (FRGS), 2011-2013.

\section{REFERENCES}

Abdelhak, S., Sulaiman, J., \& Saidatulakmal, M. (2012a). Poverty among rural communities in Kelantan and Terengganu: The role of institutions, farmers' risk management and coping strategies. Journal of Applied Sciences, 12, 125-135.

Abdelhak, S., Sulaiman, J \& Mohd, S (2012b). The Role of Assets in the Enhancement of Households' Income: A Study of Poverty Alleviation among Rural Communities of Kelantan and Terengganu. Asian Social Sciences, 8(11), 145-153.

Alam, M., Siwar, C., Molla, R., Toriman, M., \& Talib, B. (2011a). Climate change and vulnerability of paddy cultivation in North-West Selangor, Malaysia: A survey of farmers' assessment. Voice of Academia, 6(1), 45-56.

Alam, M.M., Mohd Ekhwan, T., Siwar, C., \& Talib, B. (2011b). Paddy farmers' adaptation practices to climatic vulnerabilities in Malaysia. Mitigation and Adaptation for Global Change, 16(7), 1-12. DOI: 10.1007/s11027- 011- 9333- 7. 
Alam, M., Siwar, C., Molla, R., Toriman, M., \& Talib, B. (2010). Socioeconomic impacts of climatic change on paddy cultivation: An empirical investigation in Malaysia. Journal of Knowledge Globalization, 3(2), 71-84.

Alam, MM., Siwar, C., Talib, B., Mokhtar, M \& Toriman, M.E. (2012). Climate change adaptation policy in Malaysia: Issues for agricultural sector. African Journal of Agricultural Research, 7(9), $1368-1373$.

Al-Amin, A. Q., Leal, W., de la Trinxeria, J. M., Jaafar, A. H., \& Ghani, Z. A. (2011). Assessing the impacts of climate change in the Malaysian agriculture sector and its influences in investment decision. Middle-East Journal of Scientific Research, 7(2), 225-234.

Alwang, J., Siegel, P.B., \& Jørgensen, S.L. (2002, January). Vulnerability as Viewed from Different Disciplines. Paper presented at the International Symposium. Sustaining Food Security and Managing Natural Resources in Southeast AsiaChallenges for the 21st Century. Retrieved from https://www.uni-hohenheim.de/fileadmin/einrichtungen/sfb564/ev ents/uplands2002/Full-Pap-S1-1_Siegel.pdf.

Begum, R., Siwar, C., Abidin, R., \& Pereira, J. J. (2011). Vulnerability of climate change and hardcore poverty in Malaysia. Journal of Environmental Science and Technology, 4(2), 112-117.

Bokosi, F. K. (2007). Households' poverty dynamics in Malawi: A bivariate probit analysis. Journal of Applied Sciences, 7(2), 258-262

Bourguignon, F., Goh, C., \& Kim, D. I. (2004). Estimating individual vulnerability to poverty with pseudo-panel data. World Bank Policy Research Working Paper No. 3375. Retrieved from wds.worldbank.org/servlet/WDSContentServer/WDSP/IB/-2004/0 9/08/000009486 20040908120056/Rendered/PDF/wps3375panel. pdf.

Calvo, C., \& Dercon, S. (2005, March). Measuring Individual Vulnerability. Department of Economics. Working Paper No 229 Oxford University. UK.

Chaudhuri, S. (2002): Empirical methods for assessing household vulnerability to poverty. Mimeo, Department of Economics, New York, Columbia University.

Chaudhuri, S. (2003). Assessing vulnerability to poverty: Concepts, empirical methods and illustrative examples, Working Paper, Columbia University.

Chaudhuri, S., Jalan, J., \& Suryahadi, A. (2002). Assessing household vulnerability to poverty from cross-sectional data: A methodology and estimates from Indonesia. Discussion Paper No. 0102-52. Columbia University.

Christianensen, L., \& Boisvert, R.N. (2000).On measuring household food vulnerability: Case evidence from northern Mali. Working Paper, World Bank. Retrieved from http://ageconsearch.umn.edu/bitstream/127676/2/Cornell_Dyson_ wp0005.pdf.

Dutta, I., Foster, J., \& Mishra, A. (2010). On measuring vulnerability to poverty. Working Paper. Bath, UK: Department of
Economics, University of Bath, (03/10).

http://www.bu.edu/econ/files/2012/11/dp194.pdf

Ersado, L. (2006, September). Rural vulnerability in Serbia. World Bank Policy Research. Working Paper No 4010. Retrieved from https://openknowledge.worldbank.org/bitstream/handle/10986/926 6/wps40100BOX0B311113.pdf? sequence $=1$

Fafchamps, M., and Quisumbing, A.R. (1998). Human capital, productivity, and labor allocation in rural Pakistan. Food Consumption and Nutrition Division. Paper No 48

Glewwe, P., \& Hall, G. (1998). Are some groups more vulnerable to macroeconomic risks than others. Hypothesis tests based on panel data from Peru. Journal of Development economics, 56 (1), 181-206.

Gunther, I., \& Harttgen, K. (2009). Estimating households vulnerability to idiosyncratic and covariate risks: A novel method applied in Madagascar. World Development , 37(7), 1222-1234.

Heitzmann, K., Canagarajah, R.S., \& Siegel, P.B. (2002). Guidelines for assessing the sources of risk and vulnerability. Social Protection Discussion Paper Series. No. 0218. Retrieved from http://siteresources.worldbank.org/SOCIALPROTECTION/ Resources/SP-Discussion-papers/Social-Risk-Management-DP/02 18.pdf

Hoogeveen, J., Tesliuc, E., Vakis, R., \& Dercon, S. (2004). A guide to the analysis of risk, vulnerability and vulnerable groups. World Bank, Washington. Retrieved http://siteresources.worldbank.org/INTSRM/Publications/2031631 9/RVA.pdf

Institutes of Development Studies, (IDS). (2013). Vulnerability and poverty reduction. Retrieved from http://www.ids.ac.uk/team/ vulnerability-and-poverty-reduction.

Jamalludin, S., Azlinda, A., Saidatulakmal, M., \& Senadjki, A. (2012). Vulnerability a new dimension in poverty: An empirical analysis. Humanities and Social Sciences Review, 01(02), $517-525$.

Ligon, E., \& Schechter, L. (2003). Measuring vulnerability. Economic Journal, 113, 95-102 Malaysia (2000).

Owuor, G., Ngigi, M., Ouma, A.S and Birachi, E. A. (2007). Determinants of rural poverty in africa: The case of small holder farmers in Kenya. Journal of Applied Sciences, 7(17), 2539-2543.

Siwar, C., Alam, M. M., Murad, M. W., \& Al-Amin, A. Q. (2009a). Impacts of climate change on agricultural sustainability and poverty in Malaysia. Retrieved from http://s3.amazonaws.com/academia.edu.documents/3667026/15 1 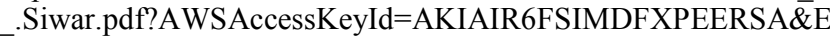 xpires $=1358820021 \&$ Signature $=i j d G w C 4 Y D 6 p R R p 2 I m x C A R s k$ $\mathrm{KzXo} \% 3 \mathrm{D}$

Wie, L. (2001). The effect of human resource development on household income in selected poor areas of rural China. Journal of Labor and Management in Development, 2(2), 1-23. 